Caroline S. Hawe

Kirsteen S. Ellis

Chris J. S. Cairns

Andrew Longmate

\section{Reply to Labeau et al.}

Accepted: 15 July 2009

Published online: 31 July 2009

(C) Springer-Verlag 2009

This reply refers to the comment available at: doi:10.1007/s00134-009-1604-3.

Sir: We thank Dr. Labeau et al. for their interest in our study of active versus passive guideline implementation to reduce ventilator-associated pneumonia (VAP) [1] and are grateful for the opportunity to reply to the important points raised.

We agree that it would have been better to measure knowledge before and after the intervention, though it is correct to point out that educational interventions or guidelines alone might be inefficient ways to drive quality improvement.
Their second point identifies the importance of sustaining an initial improvement. We have been greatly aided with this by energy from the Scottish Patient Safety Programme [2], supported by the Institute for Healthcare Improvement.

We have worked to improve compliance with bundle elements that were suboptimal in our study (namely daily sedation break and a defined weaning plan). We have worked to understand causes of noncompliance and resolve them. We have employed small tests of change, different and increased numbers of individuals with ownership and responsibilities and ongoing education. There has been enhanced team ownership of both process and outcome, and measures of these are displayed and understood within the unit. "Process" (all or nothing compliance with the "VAP prevention bundle") is currently measured continuously in contrast with our study period when it was only done intermittently. Analysis of any episodes of VAP is performed to assess whether care might have been improved in these instances.

\section{References}

1. Hawe C, Ellis K, Cairns C, Longmate A (2009) Reduction of ventilatorassociated pneumonia: active versus passive guideline implementation. Intensive Care Med 35:1180-1186

2. Scottish Patient Safety Programme (2009) http://www.patientsafetyalliance. scot.nhs.uk/programme/. Accessed 10 Jun 2009

C. S. Hawe - K. S. Ellis - C. J. S. Cairns · A. Longmate (

Department of Anaesthesia and Intensive Care Medicine, Stirling Royal Infirmary, Livilands, Stirling FK8 2AU, UK e-mail: alongmate@nhs.net

Tel.: +44-1786434476

Fax: +44-1786434476 